\title{
Identification and channel characteristics of cetacean hotspots in waterways of the eastern Sundarbans mangrove forest, Bangladesh
}

\author{
Brian D. Smith, M. A butlah Abu Diyan, Rubaiyat Mowgli Mansur \\ Elisabeth FAHRi MANSUR and Benazir Ahmed
}

\begin{abstract}
Sightings data of two freshwater-dependent cetaceans, the Ganges River dolphin Platanista gangetica gangetica and Irrawaddy dolphin Orcaella brevirostris, were recorded by captains of three nature tourism vessels operating in waterways of the eastern Sundarbans mangrove forest, Bangladesh. These data were used to investigate channel-type preferences and identify cetacean hotspots according to a scoring system based on group, individual and calf encounter rates, the co-occurrence of both species, and encounter rates in neighbouring segments recorded during monsoon, post-monsoon and dry seasons. Six 5-km segments were identified for priority conservation attention from a total of 38 that were surveyed on at least three occasions during each season. An investigation of habitat preferences evaluated $5-\mathrm{km}$ segments that had been surveyed on five or more occasions $(n=69)$ and assigned them to one of 12 categories defined by channel width, sinuosity and the number of large and small confluences. Significant differences were found between observed and expected frequencies of occurrence in the different segment categories for Ganges River dolphin groups and individuals and for Irrawaddy dolphin individuals. Both Ganges River and Irrawaddy dolphins selected channels with more than two small confluences or at least one large confluence. Understanding the preferred habitat and identifying hotspots of freshwater-dependent cetaceans in the Sundarbans is the first step of a planning process for the potential establishment of a network of protected waterways for these threatened species.
\end{abstract}

Keywords Bangladesh, encounter rate, Ganges River dolphin, habitat preference, Irrawaddy dolphin, Orcaella brevirostris, Platanista gangetica, Sundarbans

BRIAN D. SMITH* (Corresponding author) Wildlife Conservation Society, 2300 Southern Boulevard, Bronx, NY 10460, USA. E-mail bsmith@wcs.org

M. Abdullah Abu Diyan, Rubaiyat Mowgli Mansur and Elisabeth FAHRni Mansur Bangladesh Cetacean Diversity Project, Khulna, Bangladesh

Benazir Ahmed Department of Zoology, University of Chittagong, Chittagong, Bangladesh

${ }^{*}$ Current address: 27/16 Soi Naya, Moo1, Muang, Rawai, Phuket 83130 , Thailand

Received 8 April 2008. Revision requested 25 June 2008.

Accepted 17 September 2008.

\section{Introduction}

wo threatened freshwater-dependent cetaceans, the Langes River dolphin or shushuk Platanista gangetica gangetica and Irrawaddy dolphin or Iraboti Orcaella brevirostris, occur in waterways of the Sundarbans mangrove forest, Bangladesh. The Ganges River dolphin is an obligate freshwater species that ranges far upstream in the GangesBrahmaputra-Meghna rivers of Nepal, India and Bangladesh and in the comparatively much smaller Karnaphuli-Sangu rivers of southern Bangladesh. The Irrawaddy dolphin occurs in some of Asia's largest rivers (Mekong, Ayeyarwady and Mahakam) and in coastal waters of the Indo-Pacific affected by freshwater inputs (Smith \& Jefferson, 2002; Smith et al., 2007). The Ganges River and Irrawaddy dolphins are categorized as Endangered and Vulnerable, respectively, on the IUCN Red List (IUCN, 2009). Both species are threatened in the Sundarbans by incidental killing in gill nets, destruction of fish-spawning habitat through mangrove deforestation, pollution from large human population centres, the enormous bycatch of fish fingerlings and crustacean larvae in mosquito nets, and saline encroachment and excessive sedimentation from declining freshwater supplies and sea-level rise (Reeves et al., 2003; Smith et al., 2006, 2009).

The only comprehensive cetacean survey of the Sundarbans mangrove forest in Bangladesh was conducted in March 2002 along 1,510 km of waterways. The survey used double concurrent counts from independent observer teams to generate abundance estimates of 225 Ganges River dolphins $(\mathrm{CV}=12.6 \%)$ and 451 Irrawaddy dolphins $(\mathrm{CV}=9.6 \%$; Smith et al., 2006). This survey inspired us and the captains of three nature tourism vessels operated by The Guide Tours Ltd in the eastern Sundarbans of Bangladesh to initiate a cetacean monitoring programme. Here we use sightings data recorded during nature tourism cruises from April 2002 to March 2005 to identify hotspots of abundance and investigate channel-type preferences of freshwaterdependent cetaceans.

\section{Study area}

The eastern Sundarbans is defined by the Bay of Bengal in the south, Mongla Port in the north, Baleswar River in the east and Passur River in the west. It includes the Sundarbans East Sanctuary covering c. 31,000 ha of which part was designated as a UNESCO World Heritage Site in 1997 
because of its unique and diverse biological character. Major freshwater inputs to the eastern Sundarbans come from the Baleswar and Passur rivers that fan out into a complex network of estuarine waterways ranging from a few metres to a few kilometres wide and increase in salinity from northeast to south-west (Hussain \& Karim, 1994).

\section{Methods}

\section{Sighting network and channel mapping}

During nature tourism cruises conducted between 25 March 2002 and 31 March 2005 the captains and crew of the vessels M. V. Aboshar (length $35 \mathrm{~m}$, beam $8 \mathrm{~m}$, height of bridge above waterline $5 \mathrm{~m}$ and engines $265 \mathrm{hp} \times 2$ ), M. V. Chhuti (length $25 \mathrm{~m}$, beam $6.5 \mathrm{~m}$, height of bridge above waterline $4.2 \mathrm{~m}$ and engine $265 \mathrm{hp}$ ) and M. L. Bonbibi (length $21 \mathrm{~m}$, beam $6 \mathrm{~m}$, height of bridge above waterline $4.5 \mathrm{~m}$ and engine $265 \mathrm{hp}$ ) recorded observations of cetaceans on a standardized data sheet, in Bengali.

Sightings were opportunistic and no assumption was made that all dolphins present were recorded. However, sighting biases (Smith \& Reeves, 2000) were assumed to be consistent. The data sheet included entry fields for the date, time, species identity, group size, number of calves and geographical location taken with a global positioning system (GPS). Calves were defined as animals $<_{1} \mathrm{~m}$ long. Group sizes were estimated according to the best estimate of dolphins visible within the channel reach (Smith et al., 2006). The captains and crew were familiar with both cetacean species and received training in the use of the GPS, defining groups and calves and in completing the data sheets.

Data were periodically compiled, quality-checked and entered into a spreadsheet. Routes from the vessel logs were overlaid on a digitized map derived from 1:50,000 SPOT satellite imagery and divided into channel segments covering 5 linear $\mathrm{km}$ using the geographical information system ArcView v. 3.3 (ESRI, Redlands, USA). Each 5-km segment was then assigned a unique identification number and all sightings were matched to the segment number according to the location where they occurred.

\section{Scoring system for identifying hotspots}

Hotspots were identified according to a scoring system applied to segments surveyed on at least three occasions during three seasons: dry (December-March), monsoon (June-September) and post-monsoon (October-November). Insufficient data were available to include the pre-monsoon season (April-May). The top six scoring segments were emphasized in the analysis because this number was judged to be the maximum that could be realistically prioritized for focal conservation attention (e.g. establishing no-fishing zones or gear regulations), given the limits of available resources.
The scoring system used a suite of weighted variables to characterize the relative value of each segment as particularly important habitat for each species. The system gave (1) one point if the encounter rate of groups, individuals or calves was in the top $20 \%$ of all segments (calculated separately for each species and season and for groups, individuals and calves for a maximum of 18 points), (2) one point if the encounter of groups, individuals or calves was in the top $40 \%$ of all segments during all seasons (calculated separately for each species and for groups, individuals and calves for a maximum of six points), (3) two points if both Ganges and Irrawaddy dolphins were recorded in the segment during all seasons, and (4) two points if both Ganges and Irrawaddy dolphins were recorded during one season (maximum of six points). The top $40 \%$ of these scored segments were then shortlisted and each one was assigned 0.5 points for each adjacent segment that was also shortlisted in the top $40 \%$ (calculated separately for each season and for all three seasons together for a maximum of four points) and 0.25 points if the segment $5 \mathrm{~km}$ away was shortlisted in the top $40 \%$ (also calculated separately for each season and for all three seasons together for a total of two points), resulting in a grand total of 38 possible points. The aim of adjacent segment scores was to reflect the positive value of having a continuous stretch or closely spaced segments of preferred habitat vs isolated patches with energetically demanding travel distances in between.

\section{Channel-type preferences}

To investigate the frequency of dolphin occurrence according to channel characteristics, values for the mean width, sinuosity and the number of large and small confluences were calculated and assigned to each segment. Channel width was measured at the beginning, end and middle of each segment and then averaged. Segments with a width $\leq 400 \mathrm{~m}$ were classified as narrow and segments with a width $>400 \mathrm{~m}$ as wide. Sinuosity was calculated by dividing the length of each segment (i.e. $5 \mathrm{~km}$ ) by the straight-line distance between the beginning and the end points. Segments with sinuosity values of 1.0-1.49 were classified as straight and segments with a value $\geq 1.5$ were classified as sinuous. The number of large $(>400 \mathrm{~m})$ and small $(\leq 400 \mathrm{~m})$ confluences was recorded for each segment. Each segment was then coded according to the composite criteria used by Smith et al. (2009; Table 1).

\section{Results}

\section{Vessel coverage and cetacean sightings}

The nature tourism vessels surveyed a total of $26,208 \mathrm{~km}$ covering $805-\mathrm{km}$ channel segments. The captains recorded 1,005 sightings of Ganges River dolphin groups (1,993 
TABLE 1 Codes and criteria used to categorize 5-km segments along cruising routes of three nature tourism vessels operated by The Guide Tours Ltd (see text for details) in waterways of the Sundarbans mangrove forest in Bangladesh (Fig. 1; from Smith et al., 2009).

\begin{tabular}{ll}
\hline Code & Criteria \\
\hline S1 & Narrow straight with no confluence \\
S2 & Narrow straight with $1-2$ small confluences \\
S3 & Narrow straight with $>2$ small confluences or at \\
& least one large confluence \\
S4 & Narrow sinuous with no confluence \\
S5 & Narrow sinuous with $1-2$ small confluences \\
S6 & Narrow sinuous with $>2$ small confluences or at \\
& least one large confluence \\
S7 & Wide straight with no confluence \\
S8 & Wide straight with $1-2$ small confluences \\
S9 & Wide straight with $>2$ small confluences or at \\
& least one large confluence \\
S10 & Wide sinuous with no confluence \\
S11 & Wide sinuous with $1-2$ small confluences \\
S12 & Wide sinuous with $>2$ small confluences or at \\
& least one large confluence \\
\hline
\end{tabular}

individuals; $11.8 \%$ calves) and 281 sightings of Irrawaddy dolphin groups (566 individuals; 5.7\% calves; Fig. 1).

\section{Identification of cetacean hotspots}

Forty-two segments were surveyed on $<3$ occasions during each season and these were deleted from the analysis. From the remaining 38 segments the top six ranked were selected for priority conservation attention (Fig. 2). Encounter rates of Ganges River dolphins (mean $=0.46$ sightings per survey, range $=0.25-0.71$; mean $=1.12$ individuals per survey, range $=0.42-2.21$ ) were much higher than those of Irrawaddy dolphins (mean $=0.06$ sightings per survey, range $=0.02-0.11 ;$ mean $=0.15$ individuals per survey, range $=0.07-0.31$; Table 2 ). Both species were recorded in three of the top six hotspot segments in all three seasons and were recorded in the other three segments during two seasons. For comparison, only two of the remaining 32 segments included sightings of both species during three seasons.

The channel-type classifications of the top six ranked segments were narrow straight with two small confluences or at least one large confluence $\left(S_{3}\right.$, Table $\left.1 ; n=3\right)$, wide straight with at least two small confluences or one large confluence (S9; $n=1)$, narrow sinuous with more than two small confluences or at least one large confluence (S6; $\mathrm{n}=1$ ) and wide sinuous with at least two small confluences or at least one large confluence (S12; $\mathrm{n}=1$; Table 2).

\section{Channel-type preferences}

Four channel types ( $\mathrm{S}_{1}, \mathrm{~S}_{2}, \mathrm{~S}_{5}$ and $\mathrm{S}_{10}$; Table 1) were not found in the eastern Sundarbans and were therefore not

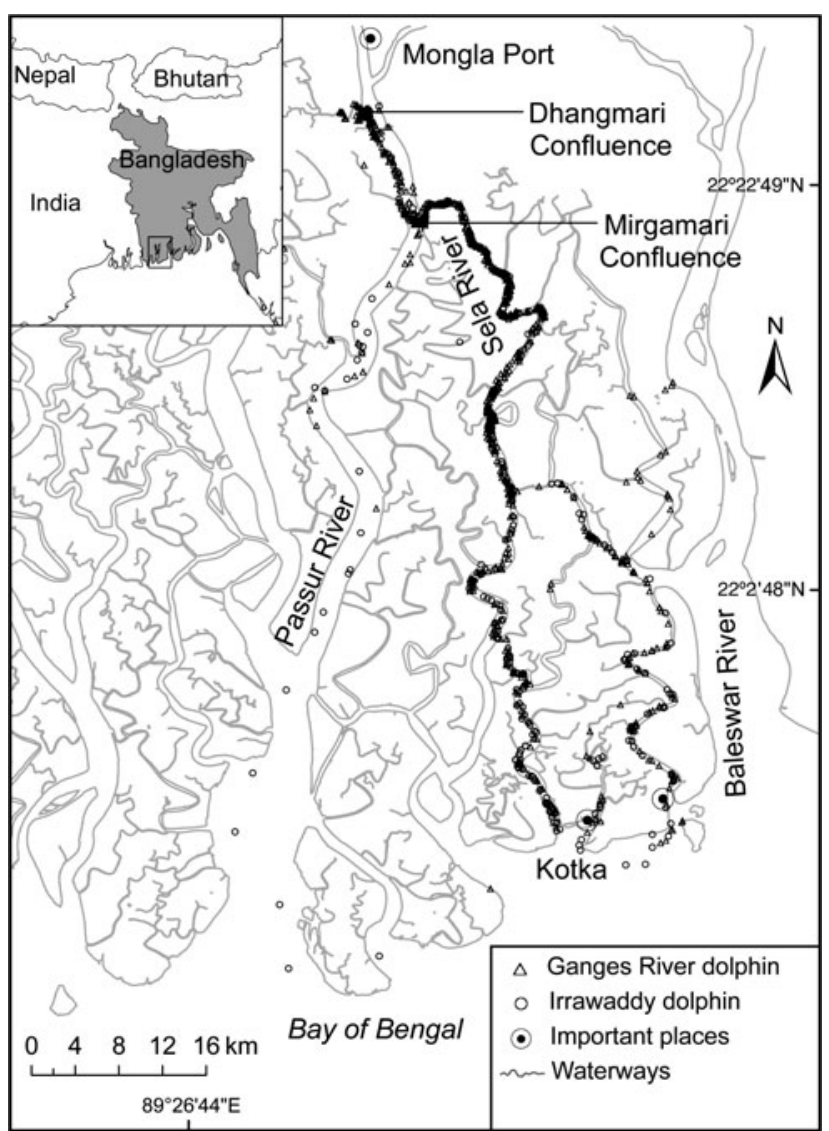

FIG. 1 The study area in the eastern Sundarbans (see rectangle on inset for location in Bangladesh), showing the locations of Ganges River and Irrawaddy dolphin sightings recorded by the captains and crew. Because of the large number of sightings the majority of the individual symbols are not visible. This map illustrates that although a hotspot conservation approach can focus protection efforts on areas of particular ecological importance it does not cover the entire range of freshwater dolphin occurrence. The map was created from satellite imagery and shows a large number of minor channels that are not navigable and where dolphins do not occur (Smith et al., 2006).

included in the channel-type preference analysis. To comply with the minimum sample size requirements of $\chi^{2}$ statistics (Zar, 1984) only those seasons and segment types with no zero values and those with $>5$ sightings or individuals were considered in the hotspot analysis. This resulted in the deletion of data from the pre-monsoon season and two additional channel types ( $\mathrm{S}_{4}$ and $\mathrm{S}_{7}$; Table 1 ), leaving a total of 69 segments that were surveyed in total on 4,928 occasions.

$\chi^{2}$ tests of pooled data from the dry, monsoon and postmonsoon seasons indicated significant differences $(\mathrm{P}<$ $0.05, \mathrm{df}=5$ ) between observed vs expected frequencies according to channel type for Ganges River dolphin groups $\left(\chi^{2}=65.2\right)$ and individuals $\left(\chi^{2}=155.1\right)$ and for Irrawaddy dolphin individuals $\left(\chi^{2}=18.9\right)$ but not for groups, possibly because of the small sample size. 


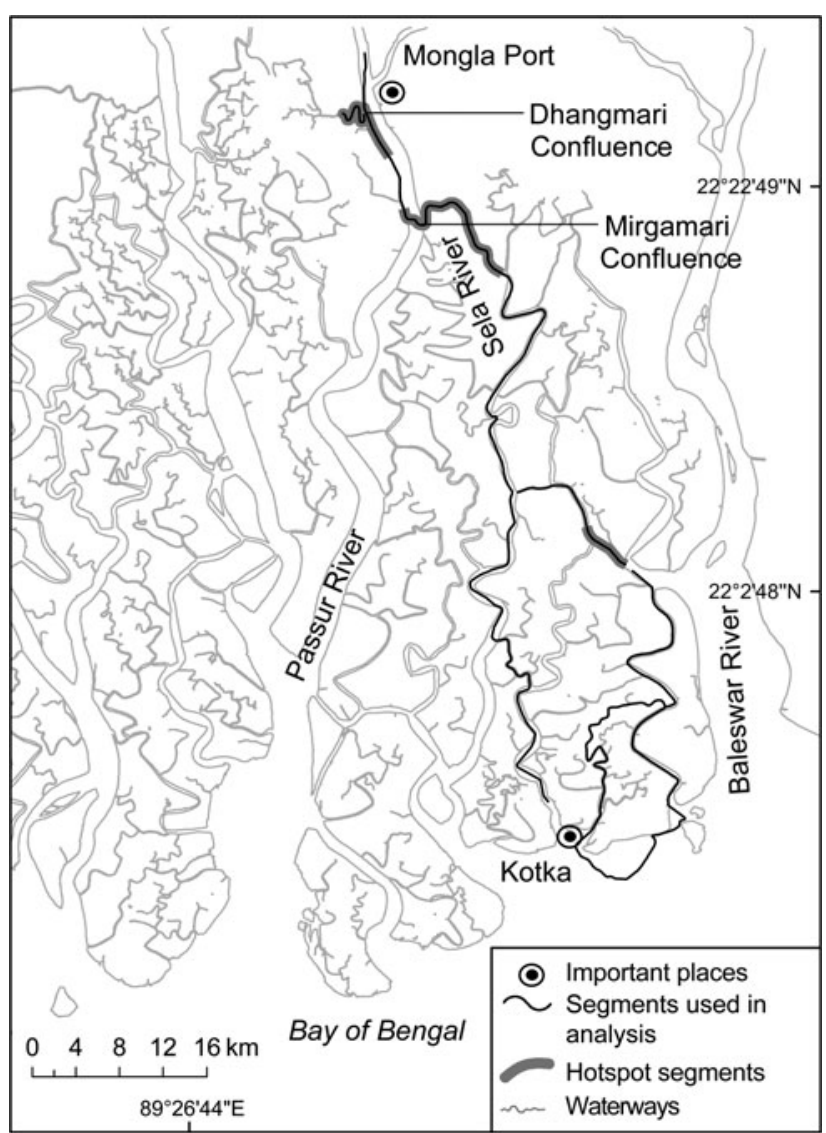

FIG. 2 The study area in the eastern Sundarbans (see inset on Fig. 1 for location) showing the 38 segments surveyed on at least three occasions during the monsoon, post-monsoon and dry seasons during 2002-2005 and the six identified hotspot segments. Note that two hotspot segments, located in the far north of the study area and inclusive of the Dhangmari confluence and the Passur River near Mongla Port, are contiguous; and three hotspot segments, located slightly to the south and inclusive of the Mirgamari confluence and beginning of the Sela River, are also contiguous.

The data set for Ganges River dolphins was sufficiently large to analyse dry, monsoon and post-monsoon seasons separately. All $\chi^{2}$ tests of frequencies of occurrence indicated significant differences $(\mathrm{P}<0.05, \mathrm{df}=5)$ between observed vs expected frequencies during the dry season $\left(\chi^{2}=33.7\right.$ for groups, $\chi^{2}=103.9$ for individuals), monsoon season $\left(\chi^{2}=\right.$ 11.7 for groups, $\chi^{2}=28.3$ for individuals) and post-monsoon season $\left(\chi^{2}=37.1\right.$ for groups, $\chi^{2}=48.6$ for individuals). Irrawaddy dolphins only had a sufficient number of sightings to analyse data separately from the dry season, which indicated significant differences $(\mathrm{P}<0.05, \mathrm{df}=5)$ between observed vs expected frequencies for individuals $\left(\chi^{2}=15.7\right)$ but not for groups.

The largest positive percentage differences among channel types from the pooled season data for observed vs expected frequencies of Ganges River dolphin individuals were for wide sinuous channels with $>2$ small confluences or at least one large confluence (S12), narrow straight channels with $>2$ small confluences or at least one large confluence $\left(\mathrm{S}_{3}\right)$ and wide straight channels with 1-2 small confluences (S8), ordered from largest to smallest. The largest positive percentage differences among channel types for observed vs expected frequencies of Irrawaddy dolphin individuals were for wide sinuous channels with $>2$ small confluences or at least one large confluence (S12), wide straight channels with $>2$ small confluences or at least one large confluence $(\mathrm{S} 9)$ and narrow straight channels with $>_{2}$ confluences or at least one large confluence (S6), ordered from largest to smallest (Table 3). The two species demonstrated inverse relationships in their preferences for narrow straight channels with $>2$ small confluences or at least one large confluence (Ganges River dolphins + and Irrawaddy dolphins -), wide straight channels with 1-2 small confluences (Ganges River dolphins + and Irrawaddy dolphins -) and wide straight channels with $>_{2}$ small confluences or at least one large confluence (Irrawaddy dolphins + and Ganges River dolphins -), probably because of the greater availability of these channel types within the respective broad-scale distribution of the two species determined by water quality gradients operating on an estuary-wide scale (Smith et al., 2009).

\section{Discussion}

The observed preference of Ganges River and Irrawaddy dolphins for channels with large and small confluences is consistent with reports elsewhere in their freshwater range (Smith, 1993; Smith et al., 1997, 1998; Baird \& Beasley, 2005; Kreb \& Budiono, 2005; Smith \& Mya, 2007). The advantages of occupying these channel types are probably related to the hydraulic refuge provided by countercurrents induced by confluences that minimize energy loss (Smith, 1993; Smith et al., 1998) and the greater biological productivity and stability (and therefore greater foraging opportunities) of low-velocity deep-water areas induced by countercurrents in running waters (Elwood et al., 1983).

The results of the hotspot analysis were generally aligned with those from the channel-type analysis, i.e. preferred channel types were well represented in the top six scoring segments, although the advantage was probably skewed towards Ganges River dolphins. The first and second topscoring segments were identified as types preferred by both species, and the third segment was identified as preferred habitat for Irrawaddy but not for Ganges River dolphins, and the fourth to sixth segments were identified as preferred habitat for Ganges River but not for Irrawaddy dolphins (Table 3).

Visual direct-count surveys for aquatic mammals (whether dedicated or opportunistic) generally underestimate occupancy and the number of animals present because of sighting biases (Marsh \& Sinclair, 1989; Smith 
TABLe 2 Summary of the number of surveys (total and during dry, monsoon and post-monsoon seasons), channel types (Table 1), and group (GER), individual (IER) and calf encounter rates (CER) of Ganges River dolphins Platanista gangetica gangetica and Irrawaddy dolphins Orcaella brevirostris, and composite scores for the top $40 \%$ ranked channel segments in the eastern Sundarbans (Fig. 1) based on sighting data collected during 2002-2005.

\begin{tabular}{|c|c|c|c|c|c|c|c|c|c|c|c|c|}
\hline \multirow[b]{2}{*}{ Rank } & \multicolumn{4}{|c|}{ No. of surveys } & \multirow[b]{2}{*}{$\begin{array}{l}\text { Channel } \\
\text { type }\end{array}$} & \multicolumn{3}{|c|}{ Ganges River dolphins } & \multicolumn{3}{|c|}{ Irrawaddy dolphins } & \multirow[b]{2}{*}{$\begin{array}{l}\text { Composite } \\
\text { score }\end{array}$} \\
\hline & Total & Dry & Monsoon & $\begin{array}{l}\text { Post- } \\
\text { monsoon }\end{array}$ & & GER & IER & CER & GER & IER & CER & \\
\hline 1 & 209 & 141 & 34 & 34 & S12 & 0.52 & 1.22 & 0.10 & 0.06 & 0.13 & 0.00 & 29 \\
\hline 2 & 42 & 19 & 14 & 9 & S6 & 0.74 & 2.74 & 0.33 & 0.10 & 0.40 & 0.05 & 27.5 \\
\hline 3 & 211 & 141 & 34 & 36 & S9 & 0.44 & 1.09 & 0.12 & 0.05 & 0.09 & 0.00 & 27 \\
\hline 4 & 198 & 135 & 34 & 29 & S3 & 0.31 & 0.58 & 0.06 & 0.03 & 0.09 & 0.02 & 23.25 \\
\hline 5 & 189 & 133 & 33 & 23 & $\mathrm{~S} 3$ & 0.60 & 1.88 & 0.27 & 0.05 & 0.10 & 0.01 & 23 \\
\hline 6 & 68 & 49 & 11 & 8 & S3 & 0.25 & 0.47 & 0.04 & 0.12 & 0.28 & 0.03 & 19 \\
\hline 7 & 107 & 68 & 22 & 17 & $\mathrm{~S} 12$ & 0.16 & 0.31 & 0.03 & 0.11 & 0.19 & 0.01 & 18.25 \\
\hline 8 & 186 & 128 & 33 & 25 & S8 & 0.48 & 0.88 & 0.12 & 0.05 & 0.09 & 0.00 & 17.5 \\
\hline 9 & 108 & 69 & 22 & 17 & S3 & 0.17 & 0.20 & 0.03 & 0.07 & 0.12 & 0.00 & 17.25 \\
\hline 10 & 192 & 132 & 33 & 27 & S9 & 0.33 & 0.60 & 0.09 & 0.04 & 0.06 & 0.01 & 16.5 \\
\hline 10 & 215 & 140 & 33 & 42 & S9 & 0.39 & 0.83 & 0.10 & 0.02 & 0.03 & 0.00 & 16.5 \\
\hline 11 & 178 & 121 & 34 & 23 & S9 & 0.30 & 0.63 & 0.04 & 0.05 & 0.08 & 0.01 & 16.25 \\
\hline 12 & 102 & 63 & 23 & 16 & S9 & 0.13 & 0.24 & 0.07 & 0.05 & 0.11 & 0.01 & 15.5 \\
\hline 13 & 110 & 70 & 22 & 18 & S9 & 0.15 & 0.23 & 0.03 & 0.06 & 0.09 & 0.00 & 14.5 \\
\hline 13 & 187 & 128 & 34 & 25 & S9 & 0.16 & 0.30 & 0.02 & 0.07 & 0.14 & 0.01 & 14.5 \\
\hline
\end{tabular}

\& Reeves, 2000; Pollock et al., 2004). To address whether or not including only segments that had been surveyed at least three times during three seasons was sufficiently conservative to minimize sighting biases, the percentage of each species detected by The Guide Tours sighting network was estimated using $\left(\mathrm{ER}_{\mathrm{gt}} / \mathrm{ER}_{\mathrm{sv}}\right) \mathrm{DT}_{\mathrm{sv}}$, where $\mathrm{ER}_{\mathrm{gt}}=$ composite encounter rate (ER) recorded by The Guide Tours sighting network in the same segments during the dry seasons of 2003-2005, $\mathrm{ER}_{\mathrm{sv}}=$ composite ER recorded in the $38 \mathrm{seg}$ ments included in the hotspot analysis during a dedicated survey in the dry season of 2002 (Smith et al., 2006), and $\mathrm{DT}_{\mathrm{sv}}=$ estimated proportion of groups detected of each species based on a mark-recapture analysis of doubleconcurrent counts made by independent observer teams during the 2002 dedicated survey (Smith et al., 2006).

$\mathrm{ER}_{\mathrm{gt}}$ was calculated as 0.05 and 0.01 groups $\mathrm{km}^{-1}$ for Ganges River and Irrawaddy dolphins, respectively. This compares to $\mathrm{ER}_{\mathrm{sv}}$ of 0.05 and 0.04 groups $\mathrm{km}^{-1}$ for Ganges
River and Irrawaddy dolphins, respectively. $\mathrm{DT}_{\mathrm{sv}}$ values taken from Smith et al. (2006) were 51.5\% (CV = 8.7\%) and $69.0 \%(\mathrm{CV}=5.3 \%)$ for Ganges River and Irrawaddy dolphins, respectively. Using these values The Guide Tours sighting network detected 51.5 and $17.3 \%$ of the total number of Ganges and Irrawaddy dolphin groups, respectively, in the sampled segments. The more quiescent surfacing characteristics of Irrawaddy vs Ganges River dolphins almost certainly account for the much lower detection rate recorded by the vessel captains vs the dedicated observers used in the survey reported in Smith et al. (2006).

This analysis implied that our scoring system was reasonably accurate at identifying priority habitat for Ganges River dolphins; MacKenzie \& Royle (2005) recommended that sampling units should be surveyed a minimum of three times for occupancy studies when detection probability is $>0.5$ per survey. However, priority habitat

TABLE 3 The total number of segments and surveys, encounter rates (ER) and relative rankings for Ganges River and Irrawaddy dolphin groups (GRP), individuals (IND) and calves (CV) in the six channel types (Table 1) in the eastern Sundarbans (Fig. 1) that were surveyed on at least five occasions.

\begin{tabular}{|c|c|c|c|c|c|c|c|c|}
\hline \multirow[b]{2}{*}{$\begin{array}{l}\text { Channel } \\
\text { type }\end{array}$} & \multirow[b]{2}{*}{$\begin{array}{l}\text { No. of } \\
\text { segments }\end{array}$} & \multirow[b]{2}{*}{$\begin{array}{l}\text { No. of } \\
\text { surveys }\end{array}$} & \multicolumn{3}{|c|}{ Ganges River dolphins } & \multicolumn{3}{|c|}{ Irrawaddy dolphins } \\
\hline & & & $\begin{array}{l}\text { GRP ER } \\
\text { (Rank) }\end{array}$ & $\begin{array}{l}\text { IND ER } \\
\text { (Rank) }\end{array}$ & $\begin{array}{l}\text { CV ER } \\
\text { (Rank) }\end{array}$ & $\begin{array}{l}\text { GRP ER } \\
\text { (Rank) }\end{array}$ & $\begin{array}{l}\text { IND ER } \\
\text { (Rank) }\end{array}$ & $\begin{array}{l}\text { CV ER } \\
\text { (Rank) }\end{array}$ \\
\hline$\overline{S 6}$ & 5 & 303 & $0.17(5)$ & $0.42(4)$ & $0.05(4)$ & $0.05(4)$ & $0.12(3)$ & $\overline{0.01(1)}$ \\
\hline S3 & 18 & 1,150 & $0.22(4)$ & $0.46(2)$ & $0.07(1)$ & $0.04(5)$ & $0.09(4)$ & $0.01(2)$ \\
\hline S9 & 32 & 2,360 & $0.16(6)$ & $0.29(6)$ & $0.03(6)$ & $0.06(2)$ & $0.12(2)$ & $0(3)$ \\
\hline S11 & 1 & 182 & $0.24(3)$ & $0.42(5)$ & $0.03(5)$ & $0.05(3)$ & $0.08(5)$ & $0(4)$ \\
\hline S12 & 4 & 429 & $0.32(1)$ & $0.66(1)$ & $0.06(2)$ & $0.06(1)$ & $0.13(1)$ & $0(5)$ \\
\hline S8 & 9 & 504 & $0.24(2)$ & $0.46(3)$ & $0.05(3)$ & $0.04(6)$ & $0.07(6)$ & $0(6)$ \\
\hline
\end{tabular}


for Irrawaddy dolphins could have been missed because the species may have been present in some segments but undetected because of sighting biases.

Our scoring system placed a strong emphasis on the recruitment value of channel segments by scoring encounter rates of calves the same as those of groups and individuals, both of which included contributions from calves. Calves accounted for 5.8 and $11.6 \%$ of the total number of Irrawaddy and Ganges River dolphins, respectively, recorded in the 38 segments included in the hotspot analysis. To investigate how this emphasis on calves may have affected the composite score values for each segment, encounter rates were calculated excluding calves and then their respective segment rankings compared. There were no changes in the segments included in the top six rankings based on composite scores except for minor changes in their order. Segment rankings of encounter rates were also directly compared for calves vs non-calves. For Ganges River dolphins there were no differences in the top six segments, although there were changes in their order. Four of these were also included in the top six hotspots identified based on composite scores. For Irrawaddy dolphins the situation was unclear, possibly because of low sample sizes. Only three of the top six ranked segments based on calf encounter rates were the same as the top six ranked segments based on non-calf encounter rates and only one of these was included in the top six hotspots identified using the composite score. Overall, these analyses indicated that the habitat selected by dolphin groups with calves vs groups without calves was similar for Ganges River dolphins and at least sometimes similar for Irrawaddy dolphins.

To investigate the effects of giving extra value to segments located adjacent to and separated by $5 \mathrm{~km}$ from other segments that were ranked in the top $40 \%$ of all segment rankings, these rankings were compared to those calculated without added points for adjacent high-value segments and those separated by $5 \mathrm{~km}$. There was no change in the segments included in the top six based on the composite score except for minor changes in their order. These results indicate that high-scoring segments were generally located close to other high-scoring segments, regardless of extra points given for their proximity. Five of the top six hotspot segments occurred in two groups of two and three segments separated by only a single non-hotspot segment (Fig. 2).

To investigate whether or not the hotspot scoring criteria accurately reflected segment preferences of both species, scores were calculated separately for Ganges River and Irrawaddy dolphins not including extra points for adjacent high-value segments and those separated by $5 \mathrm{~km}$. A potential scenario could be that there was little overlap in the habitat preferences of Ganges River and Irrawaddy dolphins and that by evaluating the species together, our scoring system prioritized segments that provided only marginal habitat for both. There were only minor differ- ences between the segment rankings based on composite scores of both species vs those based only on encounter rates for Ganges River dolphin groups, individuals and calves. The top four ranked segments based on the former were the same as those based on the latter except for changes in their order. Greater differences were found between segment rankings based on composite scores for both species vs those based only on encounter rates of Irrawaddy dolphin groups, individuals and calves. Only two of the top six hotspots identified from the composite scores were included in the top six ranked segments based on Irrawaddy dolphin encounter rates.

Overall, the top six identified hotspots accounted for 49.3 and $23.2 \%$ of all encounters of Ganges River and Irrawaddy dolphins, respectively, in the 38 segments included in the analysis. The six hotspot segments also represented 31.3 and $2.9 \%$ of all encounters of Ganges River and Irrawaddy dolphins, respectively, made during a dolphin survey of virtually all navigable channels $(1,510$ linear $\mathrm{km})$ of the Sundarbans mangrove forest in Bangladesh (Smith et al., 2006), even though these segments represented only $2.0 \%$ of the total distance covered during the survey. The apparent greater importance of the top six hotspot segments for Ganges River vs Irrawaddy dolphins is not surprising considering the location of the study area in the low-salinity eastern portion of the Sundarbans that is strongly favoured by the former species but represents the extreme distributional fringes of the latter (Smith et al., 2009).

Despite the advantages of The Guide Tours sighting network there were some shortcomings in the data. These were mostly related to the route and scheduling logistics of nature tours and the limited searching effort possible by the captains and crew who had overriding operational responsibilities for navigation and safety. The spatial and temporal distribution of survey coverage was uneven because of the large number of surveys made in segments located along preferred cruising routes.

Establishing spatial and temporal priorities for conserving large mobile predators is especially important when competing resource needs of a large, growing and generally economically impoverished human population preclude setting aside extensive areas for wildlife protection. This analysis of sighting data collected by nature tourism vessels in the eastern Sundarbans provides important insights on the locations and channel-type characteristics of priority areas for conserving two threatened freshwater-dependent cetaceans. Conservation actions that could be taken in the identified hotspot segments after consultation with local stakeholders and resource managers include establishing no-fishing zones or prohibiting fishing gears that result in incidental deaths of dolphins (e.g. gill nets and longlines) and diminish fish and crustacean recruitment (e.g. mosquito nets). A proposal has been formally submitted to the Government of Bangladesh for establishing a protected area 
network for freshwater-dependent cetaceans in the six identified hotspot segments. These segments and six others chosen randomly from the remaining segments are the current focus of a comparative study of ecological characteristsics and human impacts that will provide insights into the conservation needs of freshwater dolphins in the Sundarbans. The Guide Tours sighting network is ongoing and a high priority is to obtain data on hotspots in the western Sundarbans that are particularly important for Irrawaddy dolphins. The hotspot scoring system and use of nature tourism cruises as an opportunistic platform for obtaining cetacean sighting data have strong potential for identifying priority habitat for freshwater-dependent cetaceans in other riverine and mangrove systems.

\section{Acknowledgements}

We gratefully acknowledge the efforts of all the members of The Guide Tours Ltd, especially Captain Shahabuddin Mollah, Captain Jahidul Islam Babu, Faruk Hossain and Monirul Islam Monir. Special appreciation is due to Hasan Mansur from The Guide Tours Ltd for his unwavering support. Zahangir Alom kindly drew the figures. Funding for this study was provided by the Wildlife Conservation Society, Kerzner Marine Foundation and Marine Conservation Action Fund.

\section{References}

Baird, I.G. \& Beasley, I.L. (2005) Irrawaddy dolphin Orcaella brevirostris in the Cambodian Mekong River: an initial survey. Oryx, 39, 301-310.

Elwood, J.W., Newbold, J.D., O’Neil, R.V. \& Van Winkle, W. (1983) Resource spiraling: an operational paradigm for analyzing lotic ecosystems. In Dynamics of Lotic Ecosystems (eds T.D. Fontaine \& S.M. Bartell), pp. 3-27. Ann Arbor Science, Ann Arbor, USA.

Hussain, Z. \& Karim, A. (1994) Introduction. In Mangroves of the Sundarbans, Vol. 2, Bangladesh (eds Z. Hussain \& G. Acharya), pp. 1-10. IUCN, Bangkok, Thailand.

IUCN (2009) 2009 IUCN Red List of Threatened Species v. 2009.2. Http://www.iucnredlist.org [accessed 17 December 2009].

Kreb, D. \& Budiono (2005) Conservation management of small core areas: key to survival of a Critically Endangered population of Irrawaddy river dolphins Orcaella brevirostris in Indonesia. Oryx, 39, 178-188.

Mackenzie, D.I. \& Royle, J.A. (2005) Designing occupancy studies: general advice and allocating survey effort. Journal of Applied Ecology, 42, 1105-1114.

Marsh, H. \& SinClair, D.F. (1989) Correcting for visibility bias in strip transect aerial surveys of aquatic fauna. The Journal of Wildlife Management, 53, 1017-1024.

Pollock, K.H., Marsh, H., Bailey, L.L., Farnsworth, G.L., Simons, T.R. \& Alldredge, M.W. (2004) Separating components of detection probability in abundance estimation: an overview with diverse examples. In Sampling Rare or Elusive Species, Concepts, Designs and Techniques for Estimating Population Parameters (ed. K.P. Burnham), pp. 43-58. Island Press, Washington, DC, USA.
Reeves, R.R., Smith, B.D., Crespo, E. \& Notarbartolo Di Sciara, G. (2003) Dolphins, Whales and Porpoises: 2002-2010 Conservation Action Plan for the World's Cetaceans. IUCN, Gland, Switzerland.

S Mith, B.D. (1993) 1990 status and conservation of the Ganges river dolphin Platanista gangetica in the Karnali River, Nepal. Biological Conservation, 66, 159-169.

Smith, B.D., Braulik, G., Strindberg, S., Ahmed, B. \& Mansur, R. (2006) Abundance of Irrawaddy dolphins (Orcaella brevirostris) and Ganges River dolphins (Platanista gangetica gangetica) estimated using concurrent counts made by independent teams in waterways of the Sundarbans mangrove forest in Bangladesh. Marine Mammal Science, 22, 527-547.

Smith, B.D., Braulik, G., Strindberg, S., Mansur, R., Diyan, M.A.A. \& Ahmed, B. (2009) Habitat selection of freshwater cetaceans and the potential effects of declining freshwater flows and sea-level rise in waterways of the Sundarbans mangrove forest, Bangladesh. Aquatic Conservation Marine and Freshwater Ecosystems, 19, 209-225.

Smith, B.D., Haque, A.K.M.A., Hossain, M.S. \& Khan, A. (1998) River dolphins in Bangladesh: conservation and the effects of water development. Environmental Management, 22, 323-335.

Smith, B.D. \& JefFerson, T.A. (2002) Status and conservation of facultative freshwater cetaceans in Asia. The Raffles Bulletin of Zoology (Suppl. 10), 173-187.

Sмith, B.D. \& MyA, T.T. (2007) Status and conservation of Irrawaddy dolphins Orcaella brevirostris in the Ayeyarwady River of Myanmar. In Status and Conservation of Freshwater Populations of Irrawaddy Dolphins (eds B.D. Smith, R.G. Shore \& A. Lopez), pp. 21-40. WCS Working Paper Series 31. Wildlife Conservation Society, New York, USA.

Smith, B.D. \& Reeves, R.R. (2000) Survey methods for population assessment of Asian river dolphins. In Biology and Conservation of Freshwater Cetaceans in Asia, Occasional Paper of the IUCN Species Survival Commission, No. 23 (eds R.R. Reeves, B.D. Smith \& T. Kasuya), pp. 97-115. IUCN, Gland, Switzerland.

Smith, B.D., Shore, R.G. \& Lopez, A. (eds) (2007) Annex 1. Report on the workshop to develop a conservation action plan for freshwater populations of Irrawaddy dolphins. In Status and Conservation of Freshwater Populations of Irrawaddy Dolphins (eds B.D. Smith, R.G. Shore \& A. Lopez), pp. 90-109. WCS Working Paper Series 31. Wildlife Conservation Society, New York, USA.

Smith, B.D., Thant, H., Lwin, J.M. \& Shaw, C.D. (1997) Preliminary investigation of cetaceans in the Ayeyarwady River and northern coastal waters of Myanmar. Asian Marine Biology, 14, 173-194.

Zar, J.H. (1984) Biostatistical Analysis. Prentice-Hall, Englewood Cliffs, USA.

\section{Biographical sketches}

Brian D. Smith directs the Wildlife Conservation Society's Asian Freshwater and Coastal Cetacean Program and serves as Asia coordinator for the IUCN Species Survival Commission Cetacean Specialist Group and principal scientist for the Bangladesh Cetacean Diversity Project (BCDP). M. Abdullah Abu Diyan, Rubaiyat Mowgli Mansur and Elisabeth Fahrni Mansur compose the core team of the BCDP, the goal of which is to improve the conservation prospects of cetacean diversity in Bangladesh by building local capacity and developing a protected area network for critical cetacean habitat. BENAZIR AHMED is a supervisor of the BCDP and is also a member of the IUCN Species Survival Commission Cetacean Specialist Group. 